\title{
The mechanisms of hyphal pellet formation mediated by polysaccharides, a-1,3-glucan and galactosaminogalactan, in Aspergillus species
}

\author{
Ken Miyazawa', Akira Yoshimi ${ }^{2,3}$ and Keietsu Abe ${ }^{1,3,4^{*}}$
}

\begin{abstract}
Filamentous fungi are widely used for production of enzymes and chemicals, and are industrially cultivated both in liquid and solid cultures. Submerged culture is often used as liquid culture for filamentous fungi. In submerged culture, filamentous fungi show diverse macromorphology such as hyphal pellets and dispersed hyphae depending on culture conditions and genetic backgrounds of fungal strains. Although the macromorphology greatly affects the productivity of submerged cultures, the specific cellular components needed for hyphal aggregation after conidial germination have not been characterized. Recently we reported that the primary cell wall polysaccharide a-1,3glucan and the extracellular polysaccharide galactosaminogalactan (GAG) contribute to hyphal aggregation in Aspergillus oryzae, and that a strain deficient in both a-1,3-glucan and GAG shows dispersed hyphae in liquid culture. In this review, we summarize our current understanding of the contribution of chemical properties of a-1,3-glucan and GAG to hyphal aggregation. Various ascomycetes and basidiomycetes have a-1,3-glucan synthase gene(s). In addition, some Pezizomycotina fungi, including species used in the fermentation industry, also have GAG biosynthetic genes. We also review here the known mechanisms of biosynthesis of a-1,3-glucan and GAG. Regulation of the biosynthesis of the two polysaccharides could be a potential way of controlling formation of hyphal pellets.
\end{abstract}

Keywords: Hyphal aggregation, Filamentous fungi, Cell wall, a-1,3-Glucan, Galactosaminogalactan

\section{Introduction}

Over 1.5 million species of filamentous fungi inhabit the earth and play a central role in global material circulation as decomposers [1]. As filamentous fungi are well adapted to markedly diverse habitats, many species are used in industry, e.g. to produce enzymes and chemicals, due to their varied metabolic capabilities [2-4]. The industrial production is commonly performed by liquid cultivation of fungi, which makes it easy to supply

\footnotetext{
*Correspondence: keietsu.abe.b5@tohoku.ac.jp

${ }^{1}$ Laboratory of Applied Microbiology, Department of Microbial Biotechnology, Graduate School of Agricultural Science, Tohoku University, 468-1 Aramaki-Aoba, Aoba-ku, Sendai 980-8572, Japan Full list of author information is available at the end of the article
}

nutrients and induce gene expression. The scale of industrial fungal cultures sometimes reaches dozens of tonnes. In submerged cultivation, filamentous fungi grow in various macromorphological forms, such as pellets and pulp, depending on agitation speed, $\mathrm{pH}$, medium composition, and other conditions, and also on the genetic backgrounds of fungal strains $[4,5]$. Macromorphology greatly affects the productivity of submerged cultivation [2].

The diameters of hyphal pellets can reach several millimeters, which limits oxygen and nutrient transfer to the inner region of the pellets [6] because oxygen and nutrients can reach only $200 \mu \mathrm{m}$ from the pellet surface in submerged culture [7]. Culture broth containing fungal pellets shows Newtonian flow behavior from the 
rheological viewpoint, whereas dispersed hyphae sometimes cause high viscosity and consequently decrease the efficiency of mixing [5]. The non-Newtonian property of culture medium containing dispersed hyphae limits convective oxygen transport [4]. The preferred macromorphology of filamentous fungi in liquid culture depends on the target product. For instance, pellet form is preferable for production of citric acid by Aspergillus niger [8, 9], whereas dispersed hyphae are suitable for polygalacturonidase and glucoamylase production by $A$. niger $[6,10$, 11 ] and $\alpha$-amylase production by Aspergillus oryzae [12].

Understanding the mechanism of pellet formation in submerged cultures of filamentous fungi is important for industrial production. Prior to hyphal aggregation, conidial aggregation often takes place [13, 14]. Conidia of various filamentous fungi are coated with hydrophobins and melanins, which cause conidial aggregation via hydrophobic and electrostatic interactions, respectively [14]. The mechanism of conidial aggregation is well studied and has been covered in detail elsewhere [14, 15]. In this review, we focus on hyphal aggregation after germination. When the dormancy of conidia is broken and the conidia are swollen, the melanin and hydrophobin layer is broken, and the cell wall polysaccharides become exposed on the cell surface [14]. Here we overview the cell wall components contributing to the formation of hyphal pellets in filamentous fungi, especially in Aspergillus species.

The fungal cell wall, a complex and highly dynamic structure, is composed mainly of polysaccharides. In Aspergillus species, these polysaccharides are mostly $\alpha$-glucans $(\alpha-1,3$-glucan with a small amount of $\alpha-1,4$ glucan), $\beta$-glucans ( $\beta$-1,3-glucan with 1,6-branches), chitin, and galactomannan [16-18]. The cell wall also contains galactomannoproteins and glycosylphosphatidylinositol (GPI)-anchored proteins [19, 20]. Some fungi have an extracellular matrix (ECM), which is composed of polysaccharides, proteins, lipids, and nucleic acids [19, $21,22]$, and is associated with (or attached to) the major cell wall polysaccharides $[17,19,23]$. The ECM composition varies among fungal species [17]. In Aspergillus species, the surface of hyphal cell is decorated with the ECM material mainly composed of galactosaminogalactan (GAG), $\alpha$-1,3-glucan, and galactomannan [24, 25]. In 2010, Fontaine et al. [26] reported that $\alpha-1,3$-glucan plays a role in conidial aggregation during swelling in Aspergillus fumigatus. Through functional analysis of $\alpha-1,3-$ glucan synthase genes in Aspergillus nidulans, we found that the hyphae of an $\alpha-1,3$-glucan-deficient strain are dispersed under liquid culture conditions with shaking, whereas wild-type mycelia form pellets [27]. We further revealed that, in addition to $\alpha-1,3$-glucan, the extracellular secreted polysaccharide GAG contributes to the formation of hyphal pellets in the industrially used fungus $A$. oryzae [28]. This review describes the proposed mechanism of fungal pellet formation mediated by biochemical properties of cell wall polysaccharides, in particular $\alpha$-1,3-glucan and GAG in Aspergillus species, and outlines the potential for controlling pellet formation by regulating the biosynthesis of the polysaccharides.

\section{Hyphal aggregation factors in filamentous fungi: biological functions and biochemical properties}

Hyphal aggregation in filamentous fungi is thought to be affected by the properties of hyphal surface components. The surface of a hyphal cell is covered with the cell wall, which has essential roles in survival (i.e., maintaining the cell shape and shielding the cells from environmental stresses). The cell wall of fungi is the first component to make contact with host cells, substrates, and themselves (hyphal aggregation) [16]. Understanding the cell wall structure is essential for the control of fungal pathogenesis, industrial productivity, and so on. We recently reported that $\alpha-1,3$-glucan and GAG contribute to hyphal aggregation [28], and a study of the mechanism of hyphal aggregation mediated by the polysaccharides is ongoing. In this section, we review the biological functions of the polysaccharides related to hyphal aggregation and the mechanism of hyphal aggregation in liquid culture.

\section{a-1,3-Glucan}

By the early 1970 s, $\alpha-1,3$-glucan was known to be present in the cell wall of fungi such as A. niger, Cryptococcus neoformans, Schizosaccharomyces pombe, Polyporus species, and Paracoccidioides brasiliensis [29-32], but the biological function of $\alpha-1,3$-glucan was poorly understood. In the 1970s, Zonneveld [33-37] found that $\alpha$-1,3-glucan has a role of a reserve polysaccharide, and analyzed in detail its function related to the cell wall and cleistothecia development in A. nidulans. San-Blas et al. [38-41] first mentioned the relationship between $\alpha$-1,3-glucan and pathogenesis in P. brasiliensis in 1976. After Klimpel and Goldman [42, 43] had suggested $\alpha-1,3$-glucan as a pathogenic factor in Histoplasma capsulatum, similar biological function of $\alpha$-1,3-glucan was reported in Blastomyces dermatitidis and C. neoformans [44, 45]. Direct evidence that $\alpha$-1,3-glucan contributes to pathogenesis in $H$. capsulatum was reported in 2004 [46]. In H. capsulatum, $\alpha-1,3$-glucan is located on the surface of the cell wall and interferes with the recognition of the fungal cells by $\beta$-glucan receptors on host phagocytic cells [47]. After the whole genome analysis of many fungi, $\alpha-1,3$ glucan synthase genes were annotated in numerous fungal species, and the functional studies of these genes were pioneered in A. fumigatus [48-51]. A disruption strain of $A$. fumigatus lacking all three $\alpha-1,3$-glucan synthase 
genes $(\Delta a g s)$ lost $\alpha$-1,3-glucan from the cell wall [50] and showed decreased pathogenesis in a murine aspergillosis model [51]. Cryptococcal $\alpha-1,3$-glucan is required for the association of the capsule with cells, and the absence of $\alpha-1,3$-glucan resulted in capsule disassembly and avirulence in a mouse model $[52,53]$. In the rice blast fungus Pyricularia oryzae (Magnaporthe grisea), the surface of infectious hyphae is covered with $\alpha-1,3$-glucan, which contributes to resistance to cell wall-digesting enzymes such as $\beta-1,3$-glucanase and chitinase, resulting in inhibition of the release of pathogen-associated molecular patterns from hyphae and in infection of the host cells [54, $55]$. On the other hand, $\alpha-1,3$-glucan itself induces maturation of human dendritic cells [56], meaning that further research is needed to elucidate the contribution of $\alpha-1,3-$ glucan to virulence. Another function of $\alpha$-1,3-glucan is inhibition of adsorption of $\alpha$-amylase to cell wall chitin in $A$. oryzae $[57,58]$; under poor nutrient conditions, cell wall $\alpha-1,3$-glucan is degraded to supply glucose to hyphal cells, and then secreted $\alpha$-amylase adsorbs to chitin exposed in the cell wall, which might contribute to efficient hydrolysis of starch and subsequent sugar uptake by the cells. Bacterial $\alpha-1,3$-glucan in sticky dental plaque is an inducer substrate of mutanase, which degrades the plaque; mutanase is primarily produced by the Trichoderma genus [59]. $\alpha-1,3-$ Glucan derived from Laetiporus sulphureus [60] and Cerrena unicolor [59] is also a mutanase synthesis inducer. Antitumor activity of fungal $\alpha-1,3$-glucan $[61,62]$ and more recently its potential use as a biosorbent for heavy metals [63] have been reported. The heat resistance of ester derivatives of $\alpha$ - 1,3 -glucan is higher than that of thermoplastics such as polyethylene terephthalate or nylon $6[64,65]$. Taken together, the evidence available today indicates that $\alpha-1,3$-glucan has various biological functions, such as being a virulence factor in some pathogenic fungi, and studies on the potential application of $\alpha-1,3$-glucan as an industrial material are ongoing.

In 2010, Fontaine et al. [26] reported that $\alpha$-1,3-glucan contributes to aggregation of germinating conidia of A. fumigatus. Treatment of germinating conidia with $\alpha-1,3$-glucanase prevents the aggregation. In addition, $\alpha-1,3$-glucan-coated latex beads adhere to the surface of swollen conidia and mutan. These results demonstrate that $\alpha-1,3$-glucan plays an essential role for aggregation [26]. The hyphae of $A$. nidulans form pellets in shakeflask culture [27, 66]. Yoshimi et al. [27] first reported that the disruption of the $\alpha-1,3$-glucan synthase gene ags $B$ in $A$. nidulans resulted in a cell wall lacking $\alpha-1,3-$ glucan and in dispersed hyphae in submerged culture. $\mathrm{He}$ et al. [66] reported that hyphae formed smaller pellets in the ags $B$ disruptant in shaken liquid culture in comparison with the parental strain. Formation of small pellets by the agsB disruptant of $\mathrm{He}$ et al. [66] but not by that of Yoshimi et al. [27] might be explained by the difference in the genetic backgrounds of the two disruptants; for instance, the former might produce a larger amount of another hyphal aggregation factor, GAG (see Subsection "Galactosaminogalactan", than the latter. These results suggest that $\alpha$-1,3-glucan is a primary aggregation factor in the hyphae of $A$. nidulans. In comparison with the parental strain, the $\alpha-1,3$-glucan-deficient mutant of $A$. nidulans showed the same levels of radial growth and conidiation on agar plates [27], and its mycelial weight in liquid culture was higher [67]. In the kuro (black) koji mold Aspergillus luchuensis, although an agsE disruption mutant formed hyphal pellets, their average diameter was lower than in the wild-type strain in shake-flask culture [68]. The hyphae of wild-type $A$. oryzae form pellets similar to those of wild-type $A$. nidulans in shakeflask culture [27, 67]. Miyazawa et al. [67] reported that a triple disruption strain of $A$. oryzae defective in $\alpha-1,3-$ glucan synthase genes $(\triangle a g s A \Delta a g s B \Delta a g s C)$ lacked $\alpha-1,3-$ glucan and the diameter of its pellets was decreased by $60 \%$ compared to that of the wild-type strain in shakeflask culture. The recombinant protein productivity of the $\triangle a g s A \Delta a g s B \Delta a g s C$ mutant in flask culture was twice that of the wild-type strain [67]. Recently, Jeennor et al. [69] reported that an A. oryzae mutant defective in the ags1 (ags $B$ ) gene showed an increase in lipid productivity in submerged flask and 5-L reactor cultivation in comparison with the parental strain. Recently developed software enables automatic characterization of hyphal macromorphology including hyphal area, pellet diameter, aspect ratio, and solidity [70]. Applying this software for characterization of $\alpha-1,3$-glucan mutant hyphae could be a new approach to understand the relationship between fungal cell wall composition and morphogenesis.

Although the amounts of $\alpha-1,3$-glucan affect the macromorphology of Aspergillus species, the relationship between the chemical structure of $\alpha-1,3$-glucan and hyphal aggregation is less well understood. Miyazawa et al. [71] constructed $A$. nidulans strains overexpressing the $\alpha-1,3$-glucan synthase genes ags $A$ or ags $B$ and found that the hyphae aggregated tightly in the ags $B$ overexpressing strain (as in the wild-type strain), but loosely in the ags $A$-overexpressing strain in shake-flask culture. Several chemical analyses revealed that the peak molecular mass of $\alpha-1,3$-glucan was $372 \pm 47 \mathrm{kDa}$ in the ags $B$-overexpressing strain and $1480 \pm 80 \mathrm{kDa}$ in the ags $A$-overexpressing strain [71]. Fluorescent labeling with $\alpha$-1,3-glucan-binding domain-fused GFP revealed that $\alpha-1,3$-glucan is located in the outer layer of the cell wall in the wild-type and ags $B$-overexpressing strains, but in the inner layer in the agsA-overexpressing strain [71]. These results suggest that the degree of hyphal 
aggregation depends not only on the amount of $\alpha-1,3-$ glucan but also on its molecular mass and localization in the cell wall. The mechanism underlying different distribution of $\alpha$-1,3-glucan in the cell wall according to its molecular mass is unknown, but one possible explanation is as follows. $\alpha-1,3-$ Glucan is synthesized on the plasma membrane at the hyphal tip. Larger $\alpha$-1,3-glucan is less soluble than that with smaller molecular mass, and larger molecules are more readily insolubilized and immobilized right after their biosynthesis than are smaller molecules. $\alpha-1,3-$ Glucan from disruption strains defective in $a m y G$, which encodes intracellular $\alpha$-amylase related to biosynthesis of $\alpha$-1,3-glucan, had smaller molecular mass than that of $\alpha$-1,3-glucan from the wild type, and was localized in the outer layer of the cell wall [71], consistent with this possibility.

\section{Galactosaminogalactan}

GAG was first isolated from $A$. nidulans culture supernatant in 1970 [72], and from $A$. niger cell wall material in 1976 [73]. The presence of GAG was also reported in the culture supernatant from Penicillium frequentans in 1988 [74]. GAG was reported as one of the components of ECM in A. fumigatus in 2010 by Loussert et al. [24], and then Fontaine et al. [75] determined its detailed chemical structure. GAG is a heteropolysaccharide composed of galactopyranose and GalNAc with linear $\alpha-1,4-$ linkage; GalNAc residues are partially deacetylated to galactosamine [75]. Lee et al. [76] reported that the ratio of galactopyranose to GalNAc differs among Aspergillus species; the $A$. fumigatus GAG is composed mostly of GalNAc (>90\%), but GalNAc content is lower (70\%) in $A$. nidulans. The GalNAc-rich GAG is strongly bound to the cell wall [76]. Deacetylation of GAG is important for the adhesion of $A$. fumigatus hyphae on negatively charged surfaces [77]. It was suggested that the transcription factors StuA and MedA regulate GAG biosynthetic genes in A. fumigatus [77, 78]. GAG is synthesized by a protein complex encoded by five clustered genes ( $g t b 3$, agd3, ega3, sph3, and uge3 in A. fumigatus) [77]. GAG is a biofilm component, and the absence of GAG causes a loss of crystal violet dyability $[28,77,79]$. GAG has an immunosuppressive effect and favors infection with A. fumigatus [75]. Hyphal $\beta$-1,3-glucan is scarcely exposed because of masking by hypha-associated GAG, resulting in impaired dectin-1 ( $\beta$-1,3-glucan receptor)-mediated recognition by mammalian dendritic cells and macrophages [79]. Treatment of whole blood with purified soluble GAG increased the numbers of apoptotic neutrophils [75].

Although the hyphae of an $\alpha$-1,3-glucan-deficient mutant of $A$. oryzae form smaller pellets than those formed by wild-type hyphae in shake-flask culture [67], they are not dispersed [27]. Miyazawa et al. [28] disrupted the $s p h Z$ and $u g e Z$ genes (orthologous to sph3 and uge 3 of $A$. fumigatus, respectively) in the $\alpha-1,3-$ glucan-deficient mutant of $A$. oryzae (AG $\Delta-$ GAG $\Delta$ strain), which resulted in complete loss of GAG from the cell wall and culture supernatant and complete dispersion of the hyphae in shake-flask culture (Fig. 1). These results suggest that GAG contributes to hyphal aggregation in $A$. oryzae, in addition to $\alpha$-1,3-glucan. Interestingly, disruption of the sph $Z$ and uge $Z$ genes in the wild-type strain resulted in larger aggregates than in the wild type [28]; the cause of this phenomenon remains unclear. On agar plates, growth and morphology (i.e. branches and septa) of disruptants of GAG biosynthetic genes are similar to those of the parental strain $[28,79]$, suggesting that GAG is not essential under these conditions. In vitro aggregation assay using partially purified GAG revealed that GAG directly aggregates $A$. oryzae hyphae, and that deacetylation of GalNAc residues in GAG is important for hyphal aggregation [28]. The AG $\Delta-$ GAG $\Delta$ strain of $A$. oryzae, which is deficient in both $\alpha-1,3$-glucan and GAG, showed significantly higher recombinant protein productivity compared to those of the wild type and a mutant deficient in $\alpha$-1,3-glucan only (AG $\Delta$ strain) in submerged cultivation [28]. For the future use of the double mutant for industrial production, further evaluation of its protein and secondary metabolite productivity is ongoing in our laboratories.

\section{Contribution of the chemical properties of $\alpha-1,3-$ glucan and GAG to hyphal aggregation}

As discussed in the previous subsections, $\alpha$-1,3-glucan and/or GAG are important for hyphal aggregation in submerged culture of filamentous fungi, suggesting that the two polysaccharides contribute to hyphal pellet formation. The distribution of $\alpha-1,3$-glucan and GAG biosynthetic genes among fungi is listed in Table 1. Lee et al. [77] reported that GAG biosynthetic genes are present in some Pezizomycotina (ascomycetes) such as Aspergillus, Penicillium, and Botrytis; among basidiomycetes, only the plant pathogenic yeast Trichosporon asahii has these genes. In contrast, $\alpha-1,3$-glucan synthase genes are distributed among various ascomycetes and basidiomycetes. $\alpha-1,3-$ Glucan and/or GAG biosynthetic genes are present in most industrially relevant fungi, but are absent in Rhizopus and Trichoderma species. Therefore, controlling $\alpha-1,3$-glucan and GAG in the cell wall could help to manage the pellet formation of most filamentous fungi and subsequently ensure efficient microbial production.

The contribution of the chemical properties of $\alpha-1,3$-glucan and GAG to hyphal aggregation is shown in Fig. 2. For $\alpha-1,3$-glucan-mediated aggregation, the presence of $\alpha$-1,3-glucan in the outer layer of the cell wall is important (Fig. 2a). Lack of $\alpha$-1,3-glucan or its 


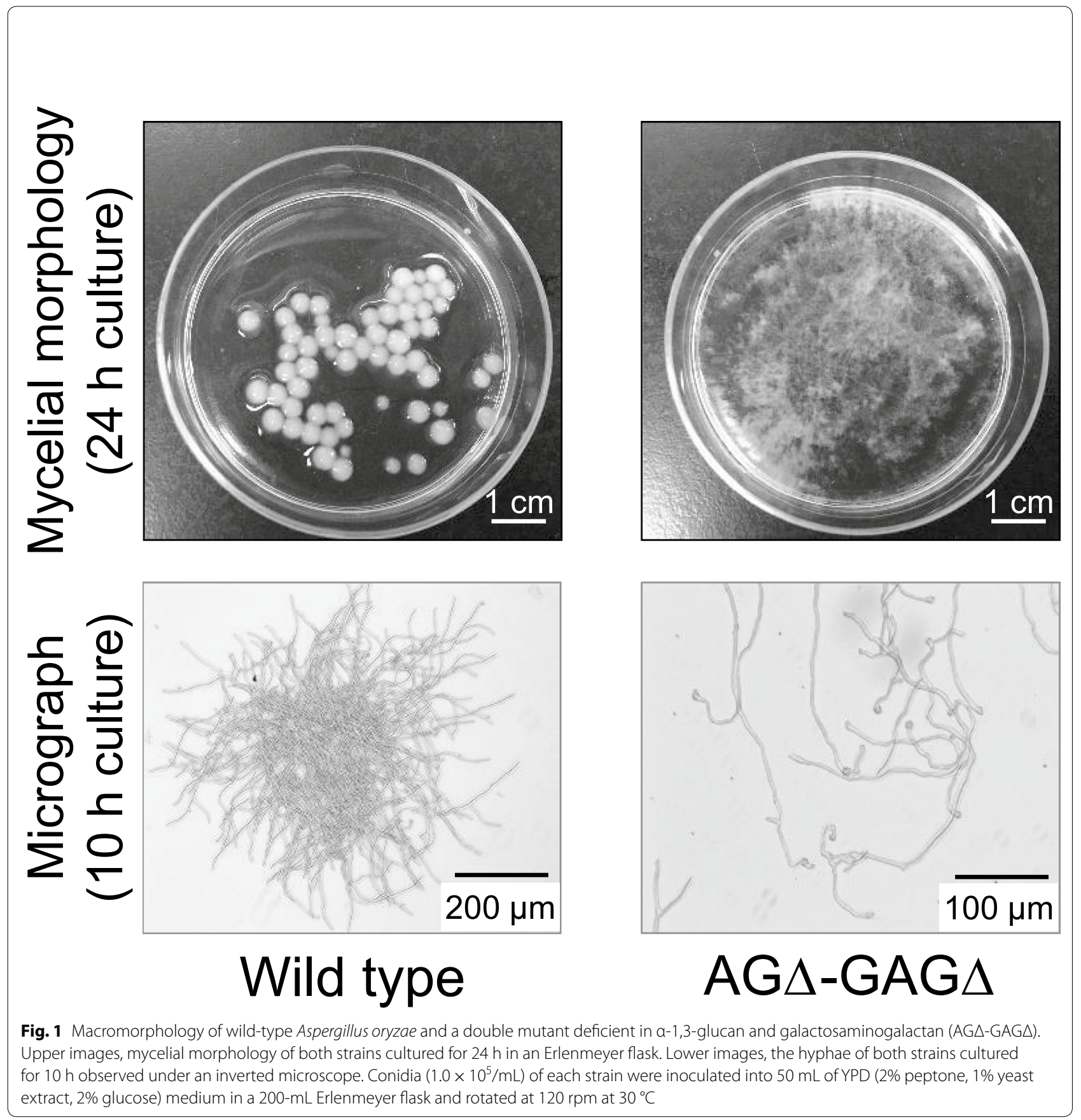

localization in the inner layer of the cell wall decreases the degree of hyphal aggregation. The primary regulatory factor for spatial localization of $\alpha$-1,3-glucan in the cell wall is its molecular mass: the small molecules are localized in the outer layer and contribute to aggregation, and the large ones are localized in the inner layer. $\alpha-1,3-$ Glucan in the inner layer is covered with $\beta$-1,3-glucan and chitin, which reduces the degree of hyphal aggregation [71]. Disruption of agd3 encoding a GalNAc deacetylase in A. fumigatus abolishes GAG deacetylation and leads to a loss of cell wall-associated GAG [77]. $N$-Acetylation of amino group in galactosamine of GAG ( 98\%) results in loss of the ability of $A$. oryzae hyphae to aggregate [28]. Thus, GAG-mediated hyphal aggregation seems to be related to the attachment of GAG to the cell surface. The ratio of GalNAc to galactopyranose and the degree of deacetylation of GalNAc residues in GAG are important for the 
Table 1 Distribution of a-1,3-glucan and galactosaminogalactan (GAG) biosynthetic genes in fungi

\begin{tabular}{|c|c|c|c|c|}
\hline Phylum & Subphylum & Species & a-1,3-Glucan & GAG \\
\hline \multirow[t]{2}{*}{ Mucoromycota } & Mucoromycotina & Mucor circinelloides & - & - \\
\hline & & Rhizopus oryzae & - & - \\
\hline \multirow[t]{20}{*}{ Ascomycota } & Taphrinomycotina & Schizosaccharomyces pombe & + & - \\
\hline & Saccharomycotina & Dekkera bruxellensis & - & - \\
\hline & & Candida albicans & - & - \\
\hline & & Kluyveromyces lactis & - & - \\
\hline & & Ashbya gossypii & - & - \\
\hline & & Zygosaccharomyces rouxii & - & - \\
\hline & & Saccharomyces cerevisiae & - & - \\
\hline & & Candida glabrata & - & - \\
\hline & Pezizomycotina & Bipolaris maydis & - & + \\
\hline & & Histoplasma capsulatum & + & - \\
\hline & & Aspergillus fumigatus & + & + \\
\hline & & Aspergillus nidulans & + & + \\
\hline & & Aspergillus oryzae & + & + \\
\hline & & Aspergillus niger & + & + \\
\hline & & Penicillium chrysogenum & + & + \\
\hline & & Botrytis cinerea & + & + \\
\hline & & Fusarium graminearum & - & - \\
\hline & & Trichoderma reesei & - & - \\
\hline & & Neurospora crassa & + & + \\
\hline & & Sordaria macrospora & + & + \\
\hline \multirow[t]{16}{*}{ Basidiomycota } & Pucciniomycotina & Rhodosporidium toruloides & - & - \\
\hline & & Puccinia graminis & + & - \\
\hline & & Wallemia sebi & - & - \\
\hline & Ustilaginomycotina & Malassezia globosa & - & - \\
\hline & & Ustilago maydis & - & - \\
\hline & Agaricomycotina & Trichosporon asahii & + & + \\
\hline & & Cryptococcus neoformans & + & - \\
\hline & & Tremella mesenterica & + & - \\
\hline & & Auricularia delicata & + & - \\
\hline & & Fomitiporia mediterranea & + & - \\
\hline & & Punctularia strigosozonata & + & - \\
\hline & & Stereum hirsutum & - & - \\
\hline & & Coniophora puteana & - & - \\
\hline & & Schizophyllum commune & + & - \\
\hline & & Coprinopsis cinerea & + & - \\
\hline & & Laccaria bicolor & + & - \\
\hline
\end{tabular}

adhesion of GAG to the cell surface (Fig. 2b). Amino groups of galactosamine residues generated by deacetylation of GalNAc residues are important for hydrogen bond formation between GAG molecules and between GAG and other cell wall components.

\section{Chemical structures and biosynthesis} of a-1,3-glucan and galactosaminogalactan

Understanding the chemical structure and biosynthesis of $\alpha$-1,3-glucan and GAG is important for the ability to regulate the degree of hyphal aggregation in liquid culture. Here we describe the current understanding of the 


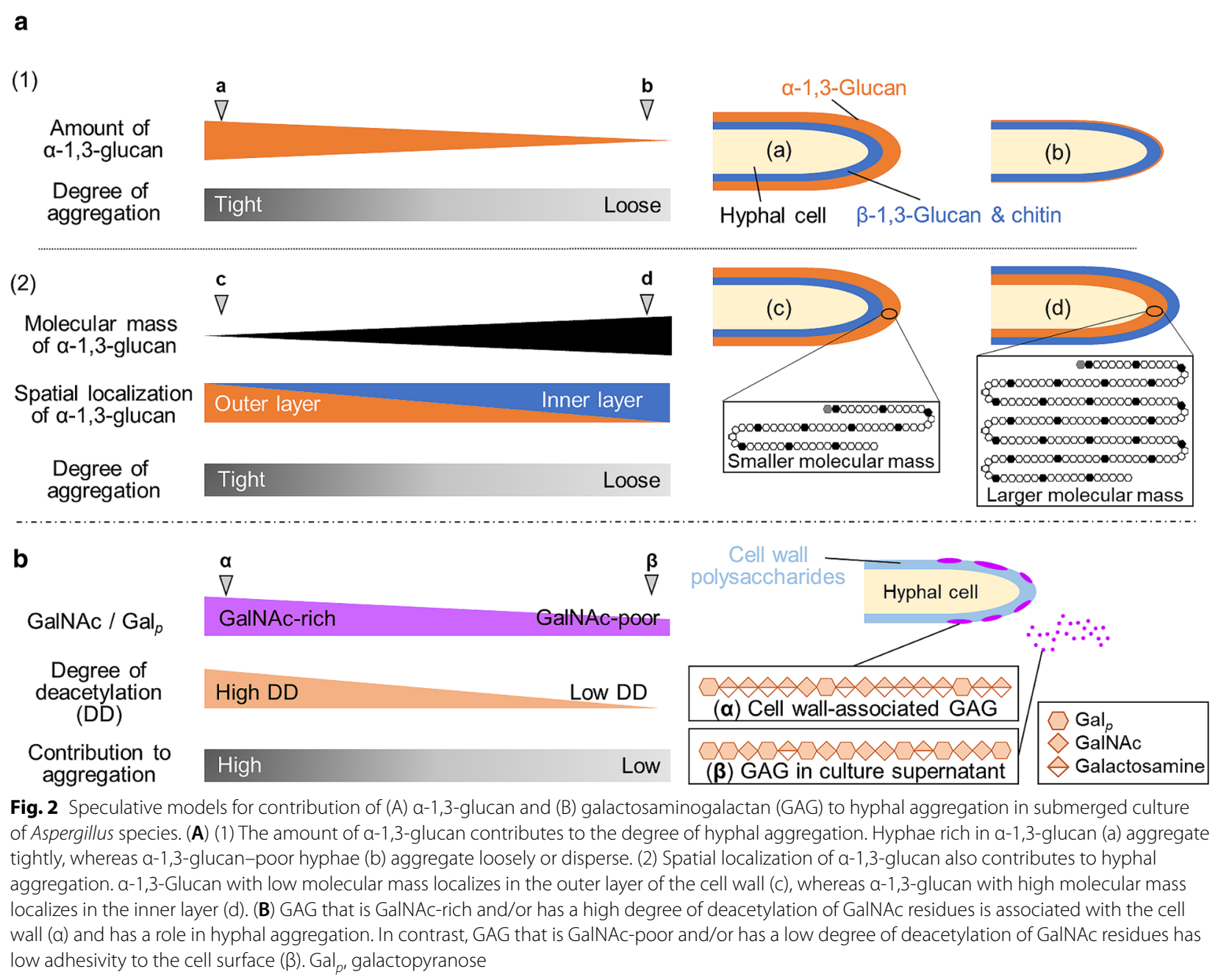

chemical structure and the mechanism of biosynthesis of these polysaccharides.

\section{a-1,3-Glucan biosynthesis}

The cell wall integrity signaling (CWIS) pathway regulates cell wall synthesis-related genes. This pathway has been studied in detail in the yeast Saccharomyces cerevisiae [80, 81]. The CWIS pathway is composed of sensor proteins, a GTPase, and a series of effectors. In particular, the protein kinase $\mathrm{C}$-activated mitogenactivated protein (MAP) kinase cascade has been well analyzed [81]. The CWIS pathway is conserved in many filamentous fungi including Aspergillus species [16, 82, 83]. Damveld et al. [84] reported that $\alpha-1,3$-glucan synthase genes are induced in the presence of a cell wall stress-inducing compound in A. niger. In S. cerevisiae, the expression of the genes involved in $\beta-1,3$-glucan and chitin synthesis is regulated through the MAP kinase Mpk1p of the CWIS pathway [85]. In contrast, $\alpha-1,3$-glucan synthase genes are regulated through the MAP kinase MpkA, whereas $\beta-1,3$-glucan and chitin synthesis-related genes are regulated by other unknown signals, in $A$. nidulans [86].

The mechanism of $\alpha$-1,3-glucan biosynthesis was first suggested from its chemical structure in the fission yeast $S$. pombe [87]. The $\alpha-1,3$-glucan synthase gene ags 1 has been isolated using forward genetics, and the Ags1p protein is thought to be composed of intracellular, extracellular, and multitransmembrane domains [87]. The presence of Ags1p (Mok1p) in the membrane fraction was confirmed [88]. Grün et al. [89] analyzed the detailed chemical structure of $\alpha$-glucan from $S$. pombe and found that its molecular mass is $42.6 \pm 5.2 \mathrm{kDa}$ and it is composed of 1,3-linked $\alpha$-glucose (90\%) and 1,4-linked $\alpha$-glucose (10\%). Each 1,4-linked $\alpha$-glucan unit $(\leq 12$ residues) interconnects two 1,3 -linked $\alpha$-glucan units (1 unit $\approx 120$ residues). 1,4-Linked $\alpha$-glucan is also located at the reducing end of the $\alpha$-glucan chain. Vos et al. [90] 
suggested that the intracellular domain is required for the biosynthesis of the $\alpha-1,4$-glucan portion.

Choma et al. [91] reported the chemical structure of water-insoluble (alkali-soluble) glucan derived from the cell wall of Aspergillus wentii. This glucan is composed of 25 subunits, each consisting of 200 residues of 1,3-linked $\alpha$-glucose; the subunits are separated by short spacers of 1,4-linked $\alpha$-glucose residues [91]. The average molecular mass of this glucan is $850 \mathrm{kDa}$ [91]. The structure of the alkali-soluble glucan from $A$. nidulans is similar to that from $A$. wentii [71]. Thus, $\alpha-1,3$-glucan from Aspergillus has a larger molecular mass and larger number of repeated subunits in its chain than that from $S$. pombe.

Grün et al. [89] speculatively described the functional domains of $\alpha-1,3$-glucan synthase of $S$. pombe. The intracellular domain contains an N-terminal Lysrich region and $\mathrm{C}$-terminal Ser-rich region, and a region with similarity to glycogen synthase and starch synthase, and is thought to have a role in the elongation of the $\alpha-1,3$-glucan chain from UDP-glucose as a sugar donor. However, no direct evidence for the function of the intracellular domain has been reported. An amino acid substitution in the intracellular domain of S. pombe Ags1 prevents accumulation of $\alpha-1,4$-glucan [90], implying that this domain might synthesize $\alpha-1,4$-glucan. The extracellular domain shares sequence similarity with bacterial $\alpha$-amylases of the glycosyl hydrolase family 13 . The temperature-sensitive $S$. pombe mutant ags 1-1 $1^{\text {ts }}$, which has a G696S substitution in the extracellular domain, synthesizes immature shortened $\alpha$-glucan without $\alpha-1,3$ glucan interconnection [89], suggesting that the extracellular domain has a role in transglycosylation of exported $\alpha-1,3$-glucan chains. The multitransmembrane domain is expected to contain 12 transmembrane helices that might form a pore-like structure. This domain is thought to export the $\alpha-1,3$-glucan polymerized by the intracellular domain [89]. This domain structure is conserved in the $\alpha$-1,3-glucan synthases from Aspergillus species [66].

In Aspergillus species, except for section Fumigati, the $\alpha$-1,3-glucan synthase gene (A. nidulans ags $B$ or its orthologue) is clustered with two $\alpha$-amylase-encoding genes [66]. In $A$. nidulans, these are the intracellular $\alpha$-amylase gene, $a m y G$, and the gene coding for GPIanchored $\alpha$-amylase, amyD. Marion et al. [92] reported that the intracellular $\alpha$-amylase from $H$. capsulatum (Amy1) is essential for biosynthesis of $\alpha$-1,3-glucan. AmyA from $P$. brasiliensis seems to have a similar role [93]. Although fungal intracellular $\alpha$-amylase is thought to synthesize 1,4 -linked $\alpha$-glucan as a primer or spacer structure for the $\alpha-1,3$-glucan chain $[92,94]$, no direct evidence has been reported. van der Kaaij et al. [94] reported that AmyD from A. niger produces maltotriose from starch with low hydrolytic activity, and has no hydrolytic activity against glycogen or UDP-glucose, so the main substrate of AmyD in vivo remains unclear. Disruption of amyG in $A$. nidulans significantly decreases the amount of $\alpha-1,3$-glucan $[66,71]$. In addition, the molecular mass of $\alpha$-1,3-glucan is significantly lower in the amyG disruptant than in wild-type $A$. nidulans and corresponds to only two $\alpha-1,3$-glucan subunits [71]. In Aspergillus species, AmyG and its orthologues probably function in spacer synthesis, and another protein might synthesize the primer for the initiation of $\alpha-1,3$-glucan polymerization.

$a m y D$ represses $\alpha-1,3$-glucan biosynthesis in $A$. nidulans $[66,95]$. He et al. [95] suggested that the mechanism of the decrease in the amount of cell wall $\alpha$-1,3-glucan by AmyD differs from that by $\alpha-1,3$-glucanase in $A$. nidulans. Aspergillus niger AgtA, encoded by a gene orthologous to $A$. nidulans amyD, uses maltopentaose or maltohexaose as substrates to produce maltooligosaccharides with a degree of polymerization of up to 28 [96]. Agt $\mathrm{A}$ uses maltose, nigerose, and nigerotriose as acceptor substrates [96].

In $H$. capsulatum, repression of the UGP1 gene encoding UTP-glucose-1-phosphate uridylyltransferase (UDPGP) causes loss of cell wall $\alpha-1,3$-glucan [92]. UDPGP converts glucose-1-phosphate and UTP to UDPglucose, suggesting that UDP-glucose might be the substrate for $\alpha-1,3$-glucan biosynthesis.

Overall, the biosynthesis of $\alpha-1,3$-glucan in Aspergillus species may proceed as follows (Fig. 3a). UDPGP synthesizes UDP-glucose from glucose-1-phosphate and UTP. Maltooligosaccharides produced by intracellular $\alpha$-amylase might act as primers for polymerization catalyzed by the intracellular domain of $\alpha$-1,3-glucan synthase. The intracellular domain catalyzes glucose polymerization from UDP-glucose as the sugar donor, resulting in synthesis of 1,3-linked $\alpha$-glucan; these reactions produce a subunit composed of 1,3-linked $\alpha$-glucan and the 1,4-linked primer at its reducing end. The subunit is exported to the outer side of the membrane through the multitransmembrane domain of $\alpha-1,3$-glucan synthase, and two subunits are interconnected by its extracellular domain. The interconnection occurs several times, resulting in a mature $\alpha-1,3$-glucan chain. AmyD represses $\alpha-1,3$-glucan accumulation, but its function during the biosynthesis remains unclear. Further studies are needed to unveil the detailed mechanism underlying the biosynthesis of $\alpha-1,3$-glucan. 


\begin{abstract}
(See figure on next page.)
Fig. 3 Speculative model for biosynthesis of (A) a-1,3-glucan and (B) galactosaminogalactan (GAG) in Aspergillus species. A AgsB, an a-1,3-glucan synthase, has three domains: extracellular, intracellular, and multitransmembrane. The likely substrate for a-1,3-glucan synthesis, UDP-glucose, is produced from glucose-6-phosphate and UTP by the UTP-glucose-1-phosphate uridylyltransferase GalF, which is encoded by a gene orthologous to H. capsulatum UGP1. Maltooligosaccharide produced by intracellular a-amylase, AmyG, might act as a primer for polymerization of glucose from UDP-glucose as the sugar donor; polymerization is performed by the intracellular domain of AgsB, resulting in a subunit composed of approximately 200 residues of 1,3-linked a-glucose with a short 1,4-linked a-glucose primer at its reducing end. The polymer synthesized by the intracellular domain is exported through a pore-like structure of the multitransmembrane domain. Then the extracellular domain catalyzes interconnection of several subunits, resulting in a mature a-1,3-glucan chain. A GPI-anchored a-amylase, AmyD, has a repressive effect on a-1,3-glucan biosynthesis, but the detailed mechanism of this effect remains unclear. G6P, glucose-6-phosphate. Protein names are for A. nidulans unless otherwise noted. B The UDP-glucose 4-epimerase Uge3 epimerizes UDP-glucose to UDP-galactopyranose and UDP- $\mathrm{N}$-acetylglucosamine to UDP-N-acetylgalactosamine (GalNAc). UDP-galactopyranose and UDP-GalNAc are expected to be polymerized by Gtb3. The polymers are thought to be exported from the cell through a pore formed by Gtb3, and then the GalNAc residues are partially deacetylated by Agd3. The deacetylated polymer is mature GAG and either associates with the cell wall or is dissolved into the culture supernatant. Sph3 hydrolyzes the GalNAc residues owing to its endo-a-1,4- $\mathrm{N}$-acetylgalactosaminidase activity. Ega3 might be released by digestion of its $\mathrm{N}$-terminal transmembrane region, and might then hydrolyze the deacetylated GAG, but no direct evidence has been reported. Protein names are for A. fumigatus
\end{abstract}

\section{GAG biosynthesis}

A GAG biosynthetic gene cluster has been identified in A. fumigatus, and the mechanism of GAG biosynthesis has been studied by analyzing the proteins encoded by the clustered genes [77]. The average molecular mass of GAG from A. fumigatus is approximately $100 \mathrm{kDa}$ (range, $10-1000 \mathrm{kDa}$ ) [75]. Deacetylation of GalNAc residues depends on the deacetylase Agd3 in A. fumigatus [77]. GAG-dependent adhesion is controlled by the degree of GalNAc deacetylation [77]. The ratio of GalNAc to galactose is also important for hyphal aggregation [79]. Thus, localization of insolubilized GAG on the cell surface via deacetylated GalNAc residues is thought to be required for hyphal aggregation.

The detailed mechanism underlying GAG biosynthesis has been reported by Speth et al. [97] in A. fumigatus. Briefly, this mechanism includes: [1] UDP-galactose and UDP-GalNAc production by Uge3 in the cytoplasm; [2] polymerization of galactose and GalNAc and export of the polymer through the membrane by Gtb3; [3] deacetylation of the polymer by Agd3 to produce mature GAG (Fig. 3b). Bamford et al. [98] recently reported that Ega3 has endo- $\alpha$-1,4-galactosaminidase activity, but the function of Ega3 during GAG biosynthesis is still unknown. The authors suggested that the $\mathrm{N}$-terminal transmembrane region of Ega3 is cleaved, and then the mature Ega3 form is released from the membrane and hydrolyzes deacetylated GAG [98] (Fig. 3b). Sph3 shows endo- $\alpha-1,4-N$-acetylgalactosaminidase activity $[99,100]$. Although disruption of the sph3 gene results in lack of GAG [99], the mechanism underlying this defect remains unclear. Although Gtb3 has not yet been characterized, it might contribute to polymerization of galactose and GalNAc, and to the outward translocation of the polymer through the pore-like region [77]. Sheppard and
Howell [21] reported that the disruption of the $g t b 3$ gene in A. fumigatus resulted in the absence of GAG. We also confirmed the absence of GAG in the A. oryzae disruptant lacking the $g t b Z$ gene (orthologous to A. fumigatus gtb3) (Miyazawa et al., unpublished results), suggesting that GtbZ is essential for GAG biosynthesis. Uge3 has epimerase activity that converts UDP-glucose into UDPgalactopyranose and UDP- $N$-acetylglucosamine into UDP-GalNAc [79, 101].

\section{Conclusions and future prospects}

Control of hyphal aggregation is an issue that needs to be resolved in industrial production using filamentous fungi. We recently reported the contribution of $\alpha-1,3$-glucan and GAG to hyphal aggregation in A. oryzae. Regulating the biosynthesis of these polysaccharides could help to optimize the degree of hyphal aggregation. Not only the amount of these polysaccharides but also their chemical structure affects hyphal aggregation. Some fungi such as Trichoderma species have no $\alpha-1,3$-glucan or GAG biosynthetic gene cluster, implying that an unknown and unique polysaccharide or protein contributing to hyphal aggregation might be found. Recently, an outstanding technique for characterizing fungal pellet structure has been reported [102]. Understanding the relationship between cell wall polysaccharides and hyphal pellet formation by taking advantage of this new technology could contribute to the improvement of the productivity of cell factories that use filamentous fungi. To further increase the productivity of proteins and chemicals in industrial fermentation using filamentous fungi, understanding the mechanism of biosynthesis of cell wall polysaccharides and their biochemical properties is necessary. 


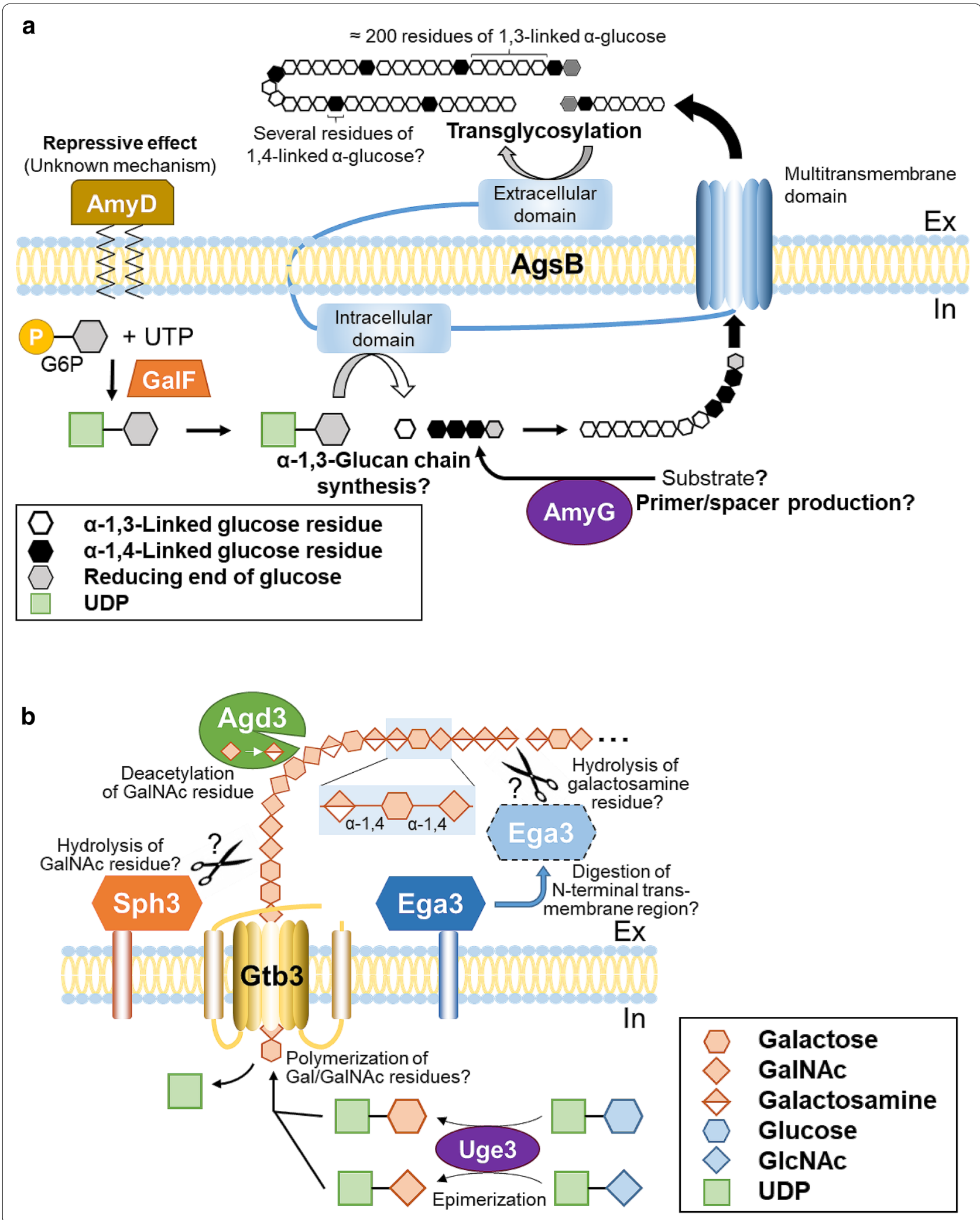




\section{Abbreviations}

CWIS: Cell wall integrity signaling; ECM: Extracellular matrix; GAG: Galactosaminogalactan; GalNAc: N-acetylgalactosamine; GPI: Glycosylphosphatidylinositol; MAP kinase: Mitogen-activated protein kinase; UDPGP: UTP-glucose-1-phosphate uridylyltransferase.

\section{Acknowledgements}

The manuscript was edited by ELSS, Inc. (http://www.elss.co.jp/en/).

\section{Authors' contributions}

$\mathrm{KM}, \mathrm{AY}$, and KA designed and wrote the manuscript. All authors read and approved the final manuscript.

\section{Funding}

This work was supported by the Japan Society for the Promotion of Science (JSPS), KAKENHI (Grant-in-Aid for Scientific Research [B] grant number 26292037 to Keietsu Abe and [C] Grant number 18K05384 to Akira Yoshimi) and a Grant-in-Aid for JSPS Fellows (Grant number 18J11870 to Ken Miyazawa). This work was also supported by the Institute for Fermentation, Osaka, Japan (Grant number L-2018-2-014) and by Adaptable and Seamless Technology Transfer Program through Target-driven R\&D (A-STEP) (grant JPMJTM19Y4) from the Japan Science and Technology Agency (JST).

\section{Availability of data and materials}

Not applicable.

\section{Ethics approval and consent to participate}

Not applicable.

\section{Consent for publication}

Not applicable.

\section{Competing interests}

The authors declare that they have no competing interests.

\begin{abstract}
Author details
${ }^{1}$ Laboratory of Applied Microbiology, Department of Microbial Biotechnology, Graduate School of Agricultural Science, Tohoku University, 468-1 Aramaki-Aoba, Aoba-ku, Sendai 980-8572, Japan. ${ }^{2}$ Laboratory of Environmental Interface Technology of Filamentous Fungi, Graduate School of Agriculture, Kyoto University, Oiwake-cho, Kitashirakawa, Sakyo-ku, Kyoto 606-8502, Japan. ${ }^{3}$ ABE-project, New Industry Creation Hatchery Center, Tohoku University, 6-6-10 Aramaki-Aoba, Aoba-ku, Sendai 980-8579, Japan. ${ }^{4}$ Laboratory of Microbial Resources, Department of Microbial Biotechnology, Graduate School of Agricultural Science, Tohoku University, 468-1 Aramaki-Aoba, Aoba-ku, Sendai 980-8572, Japan.
\end{abstract}

Received: 3 February 2020 Accepted: 12 June 2020

Published online: 01 July 2020

\section{References}

1. Hawksworth DL. The fungal dimension of biodiversity: magnitude, significance, and conservation. Mycol Res. 1991;95(6):641-55.

2. Cairns TC, Zheng XM, Zheng P, Sun JB, Meyer V. Moulding the mould: understanding and reprogramming filamentous fungal growth and morphogenesis for next generation cell factories. Biotechnol Biofuels. 2019;12:77.

3. Abe K, Gomi K, Hasegawa F, Machida M. Impact of Aspergillus oryzae genomics on industrial production of metabolites. Mycopathologia. 2006;162(3):143-53.

4. Papagianni M. Fungal morphology and metabolite production in submerged mycelial processes. Biotechnol Adv. 2004;22(3):189-259.

5. Krull R, Wucherpfennig T, Esfandabadi ME, Walisko R, Melzer G, Hempel DC, et al. Characterization and control of fungal morphology for improved production performance in biotechnology. J Biotechnol. 2013;163(2):112-23.

6. Antecka A, Bizukojc M, Ledakowicz S. Modern morphological engineering techniques for improving productivity of filamentous fungi in submerged cultures. World J Microbiol Biotechnol. 2016;32(12):193.
7. Driouch H, Hansch R, Wucherpfennig T, Krull R, Wittmann C. Improved enzyme production by bio-pellets of Aspergillus niger: targeted morphology engineering using titanate microparticles. Biotechnol Bioeng. 2012;109(2):462-71.

8. Papagianni M, Mattey M. Morphological development of Aspergillus niger in submerged citric acid fermentation as a function of the spore inoculum level. Application of neural network and cluster analysis for characterization of mycelial morphology. Microb Cell Fact. 2006;5:3.

9. Colin VL, Baigori MD, Pera LM. Tailoring fungal morphology of Aspergillus niger MYA 135 by altering the hyphal morphology and the conidia adhesion capacity: biotechnological applications. AMB Express. 2013;3(1):27.

10. Driouch H, Sommer B, Wittmann C. Morphology engineering of Aspergillus niger for improved enzyme production. Biotechnol Bioeng. 2010;105(6):1058-68.

11. Hermersdorfer $\mathrm{H}$, Leuchtenberger A, Wardsack C, Ruttloff H. Influence of culture conditions on mycelial structure and polygalacturonase synthesis of Aspergillus niger. J Basic Microbiol. 1987;27(6):309-15.

12. Carlsen M, Spohr AB, Nielsen J, Villadsen J. Morphology and physiology of an alpha Amylase producing strain of Aspergillus oryzae during batch cultivations. Biotechnol Bioeng. 1996;49(3):266-76.

13. Grimm LH, Kelly S, Krull R, Hempel DC. Morphology and productivity of filamentous fungi. Appl Microbiol Biotechnol. 2005;69(4):375-84.

14. Zhang J, Zhang J. The filamentous fungal pellet and forces driving its formation. Crit Rev Biotechnol. 2016;36(6):1066-77.

15. Veiter $L$, Rajamanickam $V$, Herwig C. The filamentous fungal pelletrelationship between morphology and productivity. Appl Microbiol Biotechnol. 2018;102(7):2997-3006.

16. Yoshimi A, Miyazawa K, Abe K. Cell wall structure and biogenesis in Aspergillus species. Biosci Biotechnol Biochem. 2016;80(9):1700-11.

17. Latgè JP. Tasting the fungal cell wall. Cell Microbiol. 2010;12(7):863-72.

18. Beauvais A, Fontaine T, Aimanianda V, Latgè JP. Aspergillus cell wall and biofilm. Mycopathologia. 2014;178(5-6):371-7.

19. Gow NAR, Latge JP, Munro CA. The fungal cell wall: structure, biosynthesis, and function. Microbiol Spectr. 2017;5(3):1. https://doi.org/10.1128/ microbiolspec.FUNK-0035-2016.

20. Samalova M, Carr P, Bromley M, Blatzer M, Moya-Nilges M, Latgé JP, et al. GPI anchored proteins in Aspergillus fumigatus and cell wall morphogenesis. Current topics in microbiology and immunologyl. 2020.

21. Sheppard DC, Howell PL. Biofilm exopolysaccharides of pathogenic fungi: lessons from bacteria. J Biol Chem. 2016;291(24):12529-37.

22. Latge J-P, Chamilos G. Aspergillus fumigatus and Aspergillosis in 2019. Clin Microbiol Rev. 2019. https://doi.org/10.1128/CMR.00140-18.

23. Lee MJ, Sheppard DC. Recent advances in the understanding of the Aspergillus fumigatus cell wall. J Microbiol. 2016;54(3):232-42.

24. Loussert C, Schmitt C, Prevost MC, Balloy V, Fadel E, Philippe B, et al. In vivo biofilm composition of Aspergillus fumigatus. Cell Microbiol. 2010;12(3):405-10.

25. Beauvais A, Schmidt C, Guadagnini S, Roux P, Perret E, Henry C, et al. An extracellular matrix glues together the aerial-grown hyphae of Aspergillus fumigatus. Cell Microbiol. 2007;9(6):1588-600.

26. Fontaine T, Beauvais A, Loussert C, Thevenard B, Fulgsang CC, Ohno $\mathrm{N}$, et al. Cell wall a1-3glucans induce the aggregation of germinating conidia of Aspergillus fumigatus. Fungal Genet Biol. 2010;47(8):707-12.

27. Yoshimi A, Sano M, Inaba A, Kokubun Y, Fujioka T, Mizutani O, et al. Functional analysis of the a-1,3-glucan synthase genes ags $A$ and ags $B$ in Aspergillus nidulans: AgsB is the major a-1,3-glucan synthase in this fungus. PLoS ONE. 2013;8(1):e54893.

28. Miyazawa K, Yoshimi A, Sano M, Tabata F, Sugahara A, Kasahara S, et al. Both galactosaminogalactan and a-1,3-glucan contribute to aggregation of Aspergillus oryzae hyphae in liquid culture. Front Microbiol. 2019;10:2090

29. Kanetsuna F, Carbonell LM. Cell wall glucans of the yeast and mycelial forms of Paracoccidioides brasiliensis. J Bacteriol. 1970;101(3):675-80.

30. Johnston IR. The partial acid hydrolysis of a highly dextrorotatory fragment of the cell wall of Aspergillus niger. Isolation of the a-(1-3)-linked dextrin series. Biochem J. 1965;96(3):659-64.

31. Bacon JSD, Jones D, Farmer VC, Webley DM. Occurrence of a(1-3)glucan in Cryptococcus, Schizosaccharomyces and Polyporus species and its hydrolysis by a Streptomyces culture filtrate lysing cell walls of Cryptococcus. Biochim Biophys Acta. 1968;158(2):313-5. 
32. Zonneveld BJ. Biochemical analysis of cell wall of Aspergillus nidulans. Biochim Biophys Acta. 1971;249(2):506-14.

33. Zonneveld BJ. Morphogenesis in Aspergillus nidulans. The significance of a a-1,3-glucan of the cell wall and a-1,3-glucanase for cleistothecium development. Biochim Biophys Acta. 1972;273(1):174-87.

34. Zonneveld BJ. Inhibitory effect of 2-deoxyglucose on cell-wall a-1,3glucan synthesis and cleistothecium development in Aspergillus nidulans. Dev Biol. 1973;34(1):1-8.

35. Zonneveld BJ. a-1,3 Glucan synthesis correlated with a-1,3 glucanase synthesis, conidiation and fructification in morphogenetic mutants of Aspergillus nidulans. J Gen Microbiol. 1974;81(2):445-51.

36. Zonneveld BJM. Sexual differentiation in Aspergillus nidulans-requirement for manganese and its effect on a-1,3 glucan synthesis and degradation. Arch Microbiol. 1975;105(2):101-4.

37. Zonneveld BJM. Sexual differentiation in Aspergillus nidulans-requirement for manganese and correlation between phosphoglucomutase and synthesis of reserve material. Arch Microbiol. 1975;105(2):105-8.

38. San-Blas G, Vernet D. Induction of the synthesis of cell wall a-1,3-glucan in the yeastlike form of Paracoccidioides brasiliensis strain IVIC Pb9 by fetal calf serum. Infect Immun. 1977;15(3):897-902.

39. San-Blas G, San-Blas F, Serrano LE. Host-parasite relationships in the yeastlike form of Paracoccidioides brasiliensis strain IVIC Pb9. Infect Immun. 1977;15(2):343-6.

40. Hallak J, San-Blas F, San-Blas G. Isolation and wall analysis of dimorphic mutants of Paracoccidioides brasiliensis. Sabouraudia. 1982;20(1):51-62.

41. San-Blas F, San-Blas G, Cova LJ. A morphological mutant of Paracoccidioides brasiliensis strain IVIC Pb9. Isolation and wall characterization. J Gen Microbiol. 1976;93(2):209-18.

42. Klimpel KR, Goldman WE. Isolation and characterization of spontaneous avirulent variants of Histoplasma capsulatum. Infect Immun. 1987;55(3):528-33.

43. Klimpel KR, Goldman WE. Cell walls from avirulent variants of Histoplasma capsulatum lack a-(1,3)-glucan. Infect Immun. 1988;56(11):2997-3000.

44. Hogan LH, Klein BS. Altered expression of surface a-1,3-glucan in genetically related strains of Blastomyces dermatitidis that differ in virulence. Infect Immun. 1994;62(8):3543-6.

45. James PG, Cherniak R, Jones RG, Stortz CA, Reiss E. Cell-wall glucans of Cryptococcus neoformans CAP-67. Carbohydr Res. 1990;198(1):23-38.

46. Rappleye CA, Engle JT, Goldman WE. RNA interference in Histoplasma capsulatum demonstrates a role for a-(1,3)-glucan in virulence. Mol Microbiol. 2004;53(1):153-65.

47. Rappleye CA, Eissenberg LG, Goldman WE. Histoplasma capsulatum $a-(1,3)$-glucan blocks innate immune recognition by the $\beta$-glucan receptor. Proc Natl Acad Sci USA. 2007;104(4):1366-70.

48. Beauvais A, Maubon D, Park S, Morelle W, Tanguy M, Huerre M, et al. Two a(1-3) glucan synthases with different functions in Aspergillus fumigatus. Appl Environ Microbiol. 2005;71(3):1531-8.

49. Maubon D, Park S, Tanguy M, Huerre M, Schmitt C, Prevost MC, et al. AGS3, an a(1-3)glucan synthase gene family member of Aspergillus fumigatus, modulates mycelium growth in the lung of experimentally infected mice. Fungal Genet Biol. 2006;43(5):366-75.

50. Henry C, Latgè JP, Beauvais A. a1,3 Glucans are dispensable in Aspergillus fumigatus. Eukaryot Cell. 2012;11(1):26-9.

51. Beauvais A, Bozza S, Kniemeyer O, Formosa C, Balloy V, Henry C, et al. Deletion of the $a-(1,3)$-glucan synthase genes induces a restructuring of the conidial cell wall responsible for the avirulence of Aspergillus fumigatus. PLoS Pathog. 2013;9(11):e1003716.

52. Reese AJ, Doering TL. Cell wall a-1,3-glucan is required to anchor the Cryptococcus neoformans capsule. Mol Microbiol. 2003;50(4):1401-9.

53. Reese AJ, Yoneda A, Breger JA, Beauvais A, Liu H, Griffith CL, et al. Loss of cell wall a(1-3) glucan affects Cryptococcus neoformans from ultrastructure to virulence. Mol Microbiol. 2007;63(5):1385-98.

54. Fujikawa T, Kuga Y, Yano S, Yoshimi A, Tachiki T, Abe K, et al. Dynamics of cell wall components of Magnaporthe grisea during infectious structure development. Mol Microbiol. 2009;73(4):553-70.

55. Fujikawa T, Sakaguchi A, Nishizawa Y, Kouzai Y, Minami E, Yano S, et al. Surface a-1,3-glucan facilitates fungal stealth infection by interfering with innate immunity in plants. PLoS Pathog. 2012;8(8):e1002882.

56. Stephen-Victor E, Karnam A, Fontaine T, Beauvais A, Das M, Hegde P, et al. Aspergillus fumigatus cell wall a-(1,3)-glucan stimulates regulatory
T-cell polarization by inducing PD-L1 expression on human dendritic cells. J Infect Dis. 2017;216(10):1281-94.

57. Zhang S, Sato H, Ichinose S, Tanaka M, Miyazawa K, Yoshimi A, et al. Cell wall a-1,3-glucan prevents alpha-amylase adsorption onto fungal cell in submerged culture of Aspergillus oryzae. J Biosci Bioeng. 2017;124(1):47-53.

58. Sato H, Toyoshima Y, Shintani T, Gomi K. Identification of potential cell wall component that allows Taka-amylase A adsorption in submerged cultures of Aspergillus oryzae. Appl Microbiol Biotechnol. 2011;92(5):961-9.

59. Osińska-Jaroszuk M, Wiater A, Choma A, Pleszczyńska M, Jaszek M, Janusz $\mathrm{G}$, et al. ( $1 \rightarrow$ 3)-a-d-Glucan from fruiting body and mycelium of Cerrena unicolor (Bull.) Murrill: structural characterization and use as a novel inducer of mutanase. Int J Polymer Sci. 2017;2017:1-9.

60. Wiater A, Szczodrak J, Pleszczynska M. Mutanase induction in Trichoderma harzianum by cell wall of Laetiporus sulphureus and its application for mutan removal from oral biofilms. J Microbiol Biotechnol. 2008;18(7):1335-41.

61. Wasser SP. Medicinal mushrooms as a source of antitumor and immunomodulating polysaccharides. Appl Microbiol Biotechnol. 2002;60(3):258-74.

62. Wiater A, Paduch R, Choma A, Pleszczynska M, Siwulski M, Dominik J, et al. Biological study on carboxymethylated (1 $\longrightarrow 3$ )-a-D-glucans from fruiting bodies of Ganoderma lucidum. Int J Biol Macromol. 2012;51(5):1014-23.

63. Nowak K, Wiater A, Choma A, Wiacek D, Bieganowski A, Siwulski M, et al. Fungal $(1 \longrightarrow 3)$-a-d-glucans as a new kind of biosorbent for heavy metals. Int J Biol Macromol. 2019;137:960-5.

64. Puanglek S, Kimura S, Enomoto-Rogers Y, Kabe T, Yoshida M, Wada M, et al. In vitro synthesis of linear a-1,3-glucan and chemical modification to ester derivatives exhibiting outstanding thermal properties. Sci Rep. 2016;6:30479.

65. Puanglek S, Kimura S, Iwata T. Thermal and mechanical properties of tailor-made unbranched a-1,3-glucan esters with various carboxylic acid chain length. Carbohydr Polym. 2017;169:245-54.

66. He XX, Li SN, Kaminskyj SGW. Characterization of Aspergillus nidulans a-glucan synthesis: roles for two synthases and two amylases. Mol Microbiol. 2014;91(3):579-95.

67. Miyazawa K, Yoshimi A, Zhang S, Sano M, Nakayama M, Gomi K, et al. Increased enzyme production under liquid culture conditions in the industrial fungus Aspergillus oryzae by disruption of the genes encoding cell wall a-1,3-glucan synthase. Biosci Biotechnol Biochem. 2016;80(9):1853-63.

68. Tokashiki J, Hayashi R, Yano S, Watanabe T, Yamada O, Toyama H, et al. Influence of a-1,3-glucan synthase gene agsE on protoplast formation for transformation of Aspergillus luchuensis. J Biosci Bioeng. 2019;128(2):129-34.

69. Jeennor S, Anantayanon J, Panchanawaporn S, Chutrakul C, Laoteng K. Morphologically engineered strain of Aspergillus oryzae as a cell chassis for production development of functional lipids. Gene. 2019;718:144073.

70. Cairns TC, Feurstein C, Zheng X, Zheng P, Sun J, Meyer V. A quantitative image analysis pipeline for the characterization of filamentous fungal morphologies as a tool to uncover targets for morphology engineering: a case study using apID in Aspergillus niger. Biotechnol Biofuels. 2019;12:149.

71. Miyazawa K, Yoshimi A, Kasahara S, Sugahara A, Koizumi A, Yano S, et al. Molecular mass and localization of a-1,3-glucan in cell wall control the degree of hyphal aggregation in liquid culture of Aspergillus nidulans. Front Microbiol. 2018;9:2623.

72. Gorin PAJ, Eveleigh DE. Extracellular 2-acetamido-2-deoxy-D-galacto-Dgalactan from Aspergillus nidulans. Biochem. 1970;9(25):5023-7.

73. Bardalaye PC, Nordin JH. Galactosaminogalactan from cell walls of Aspergillus niger. J Bacteriol. 1976;125(2):655-69.

74. Guerrero C, Prieto A, Leal JA. Extracellular galactosaminogalactan from Penicillium frequentans. Microbiología Sem. 1988:4:39-46.

75. Fontaine T, Delangle A, Simenel C, Coddeville B, Van Vliet SJ, Van Kooyk Y, et al. Galactosaminogalactan, a new immunosuppressive polysaccharide of Aspergillus fumigatus. PLoS Pathog. 2011;7(11):e1002372.

76. Lee MJ, Liu H, Barker BM, Snarr BD, Gravelat FN, Al Abdallah Q, et al. The fungal exopolysaccharide galactosaminogalactan mediates virulence 
by enhancing resistance to neutrophil extracellular traps. PLoS Pathog. 2015;11(10):e1005187.

77. Lee MJ, Geller AM, Bamford NC, Liu H, Gravelat FN, Snarr BD, et al. Deacetylation of fungal exopolysaccharide mediates adhesion and biofilm formation. mBio. 2016;7(2):e00252-16.

78. Gravelat FN, Ejzykowicz DE, Chiang LY, Chabot JC, Urb M, Macdonald $\mathrm{KD}$, et al. Aspergillus fumigatus MedA governs adherence, host cell interactions and virulence. Cell Microbiol. 2010;12(4):473-88.

79. Gravelat FN, Beauvais A, Liu H, Lee MJ, Snarr BD, Chen D, et al. Aspergillus galactosaminogalactan mediates adherence to host constituents and conceals hyphal beta-glucan from the immune system. PLoS Pathog. 2013;9(8):e1003575

80. Levin DE. Cell wall integrity signaling in Saccharomyces cerevisiae. Microbiol Mol Biol Rev. 2005;69(2):262-91.

81. Levin DE. Regulation of cell wall biogenesis in Saccharomyces cerevisiae: the cell wall integrity signaling pathway. Genetics. 2011;189(4):1145-75.

82. Dichtl K, Samantaray S, Wagener J. Cell wall integrity signalling in human pathogenic fungi. Cell Microbiol. 2016;18(9):1228-38.

83. Valiante $V$. The cell wall integrity signaling pathway and its involvement in secondary metabolite production. J Fungi (Basel). 2017:3(4):68.

84. Damveld RA, vanKuyk PA, Arentshorst M, Klis FM, van den Hondel CA, Ram AF. Expression of agsA, one of five 1,3-a-D-glucan synthase-encoding genes in Aspergillus niger, is induced in response to cell wall stress. Fungal Genet Biol. 2005;42(2):165-77.

85. Jung US, Levin DE. Genome-wide analysis of gene expression regulated by the yeast cell wall integrity signalling pathway. Mol Microbiol. 1999;34(5):1049-57.

86. Fujioka T, Mizutani O, Furukawa K, Sato N, Yoshimi A, Yamagata Y, et al. MpkA-dependent and-independent cell wall integrity signaling in Aspergillus nidulans. Eukaryot Cell. 2007;6(8):1497-510.

87. Hochstenbach F, Klis FM, van den Ende H, van Donselaar E, Peters PJ, Klausner RD. Identification of a putative a-glucan synthase essential for cell wall construction and morphogenesis in fission yeast. Proc Natl Acad Sci USA. 1998;95(16):9161-6.

88. Katayama S, Hirata D, Arellano M, Perez P, Toda T. Fission yeast a-glucan synthase Mok1 requires the actin cytoskeleton to localize the sites of growth and plays an essential role in cell morphogenesis downstream of protein kinase C function. J Cell Biol. 1999;144(6):1173-86.

89. Grün $\mathrm{CH}$, Hochstenbach F, Humbel BM, Verkleij AJ, Sietsma JH, Klis FM, et al. The structure of cell wall a-glucan from fission yeast. Glycobiology. 2005;15(3):245-57.

90. Vos A, Dekker N, Distel B, Leunissen JA, Hochstenbach F. Role of the synthase domain of Ags $1 p$ in cell wall a-glucan biosynthesis in fission yeast. J Biol Chem. 2007;282(26):18969-79.

91. Choma A, Wiater A, Komaniecka I, Paduch R, Pleszczynska M, Szczodrak $J$. Chemical characterization of a water insoluble $(1 \longrightarrow 3)$-a-D-glucan from an alkaline extract of Aspergillus wentii. Carbohydr Polym. 2013;91(2):603-8.
92. Marion CL, Rappleye CA, Engle JT, Goldman WE. An a-(1,4)-amylase is essential for a-(1,3)-glucan production and virulence in Histoplasma capsulatum. Mol Microbiol. 2006;62(4):970-83.

93. Camacho E, Sepulveda VE, Goldman WE, San-Blas G, Nino-Vega GA. Expression of Paracoccidioides brasiliensis AMY1 in a Histoplasma capsulatum amy 1 mutant, relates an a-(1,4)-amylase to cell wall a-(1,3)glucan synthesis. PLoS ONE. 2012;7(11):e50201.

94. van der Kaaij RM, Janecek S, van der Maarel MJ, Dijkhuizen L. Phylogenetic and biochemical characterization of a novel cluster of intracellular fungal a-amylase enzymes. Microbiology. 2007;153:4003-15.

95. He X, Li S, Kaminskyj S. An amylase-like protein, AmyD, is the major negative regulator for a-glucan synthesis in Aspergillus nidulans during the asexual life cycle. Int J Mol Sci. 2017;18(4):695.

96. van der Kaaij RM, Yuan XL, Franken A, Ram AF, Punt PJ, van der Maarel $M J$, et al. Two novel, putatively cell wall-associated and glycosylphosphatidylinositol-anchored a-glucanotransferase enzymes of Aspergillus niger. Eukaryot Cell. 2007;6(7):1178-88.

97. Speth C, Rambach G, Lass-Flörl C, Howell PL, Sheppard DC. Galactosaminogalactan (GAG) and its multiple roles in Aspergillus pathogenesis. Virulence. 2019:23:1-8.

98. Bamford NC, Le Mauff F, Subramanian AS, Yip P, Millan C, Zhang Y, et al. Ega3 from the fungal pathogen Aspergillus fumigatus is an endo-a1,4-galactosaminidase that disrupts microbial biofilms. J Biol Chem. 2019;294(37):13833-49.

99. Bamford NC, Snarr BD, Gravelat FN, Little DJ, Lee MJ, Zacharias CA, et al. Sph3 is a glycoside hydrolase required for the biosynthesis of galactosaminogalactan in Aspergillus fumigatus. J Biol Chem. 2015;290(46):27438-50.

100. Le Mauff F, Bamford NC, Alnabelseya N, Zhang Y, Baker P, Robinson H, et al. Molecular mechanism of Aspergillus fumigatus biofilm disruption by fungal and bacterial glycoside hydrolases. J Biol Chem. 2019;294(28):10760-72.

101. Lee MJ, Gravelat FN, Cerone RP, Baptista SD, Campoli PV, Choe SI, et al. Overlapping and distinct roles of Aspergillus fumigatus UDP-glucose 4-epimerases in galactose metabolism and the synthesis of galactosecontaining cell wall polysaccharides. J Biol Chem. 2014;289(3):1243-56.

102. Schmideder S, Barthel L, Friedrich T, Thalhammer M, Kovačević T, Niessen $\mathrm{L}$, et al. An X-ray microtomography-based method for detailed analysis of the three-dimensional morphology of fungal pellets. Biotechnol Bioeng. 2019;116(6):1355-65.

\section{Publisher's Note}

Springer Nature remains neutral with regard to jurisdictional claims in published maps and institutional affiliations.

Ready to submit your research? Choose BMC and benefit from:

- fast, convenient online submission

- thorough peer review by experienced researchers in your field

- rapid publication on acceptance

- support for research data, including large and complex data types

- gold Open Access which fosters wider collaboration and increased citations

- maximum visibility for your research: over $100 \mathrm{M}$ website views per year

At BMC, research is always in progress.

Learn more biomedcentral.com/submissions 